\title{
Assessment of Prevalence of Malnutrition among Children Age 6-59 Months at Woreda 06, Gulele Subcity, Addis Ababa, Ethiopia, 2017
}

\section{Cheru Kore ${ }^{1^{*}}$ and Abreham Ketema ${ }^{2}$}

${ }^{1}$ Department of Public Health and Nursing, Rift Valley University, Addis Ababa, Ethiopia

${ }^{2}$ Department of Public Health; Rift Valley University, Addis Ababa, Ethiopia

"Corresponding author: Cheru Kore, Research and publication officer, Department of Public Health and Nursing, Rift Valley University, Addis Ababa, Bole 0000, Ethiopia, Tel: +251912441527; E-mail: cheru_kore@yahoo.com

Received date: July 13, 2018; Accepted date: October 23, 2018; Published date: October 30, 2018

Copyright: @ 2018 Kore $\mathrm{C}$, et al. This is an open-access article distributed under the terms of the Creative Commons Attribution License, which permits unrestricted use, distribution, and reproduction in any medium, provided the original author and source are credited.

\begin{abstract}
Background: Child illness and death in Ethiopia are primarily due to five common childhood illnesses, namely pneumonia (ARI), diarrhea, malaria, measles, and malnutrition and often combination of these conditions.

Objective: Assessment prevalence of malnutrition and associated factors among children aged 6-59 months at woreda 06 Addis Hiwot health center, Gulele sub city, Addis Ababa, Ethiopia, 2017.

Methods: A cross sectional institution based quantitative study was carried out in Gulele Sub-city woreda 06 . The sample size was determined using a single population proportion. The sample size thus was 359 Adopted, modified and pre- tested interview questionnaire is used. The data collectors are those trained health professional working out the study facility. Data is collected from mothers or care takers who were come to Gulele sub-city woreda 06 Addis Hiwot Health center by giving structured questionnaire.
\end{abstract}

Result: In this study Growth monitoring, weight for age of children shows, normal 165 (46\%), mild 160 (44.6\%) moderate $34(9.5 \%)$. Weight for height, normal $150(41.8 \%)$, mild $176(49 \%)$ moderate $23(6.4 \%)$ and severe wasting 4 (1.1\%). MUAC measurement shows normal $159(44.3 \%)$ wasted $160(44.6 \%)$.

Conclusion \& Recommendation: The majority of children assessed were in age group of 6-12 months with unknown weight during their neonatal period presented at sick baby clinic. Since malnutrition results from multi socioeconomic factors multisectoral collaboration should implemented for alleviation of malnutrition problem from woreda health office, Addis Hiwot health center, woreda finance and economic office and woreda urban agriculture extension.

Keywords: Assessment; Prevalence of malnutrition; Children

\section{Background}

Malnutrition among the under-5 years is a leading factor underlying child mortality in Sub-Saharan Africa, and contributes to 2.2 million deaths and a fifth of all disability adjusted-life-years lost worldwide for children under five years old [1]. The nutritional status of young children is one of the most sensitive indicators of sudden changes in health status, reflecting the quality health service delivery. Malnutrition in children can take a form of stunting, wasting or underweight [2]. Stunting, which is height for age below that expected on the basis of the International growth reference is a very serious type of malnutrition in that it develops slowly through time before it is evident. The high prevalence of malnutrition among the children reflects inadequate health services, poor water and sanitation, poor maternal and child care practices and insufficient access to food. This is caused by poor health service delivery at village level and subsequent health system levels.

Nutritional status is the result of complex interactions between food consumption and the overall status of health and health care practices. Numerous socioeconomic and cultural factors influence patterns of feeding children and the nutritional status of women and children. The period from birth to age two is especially important for optimal growth, health, and development. Unfortunately, this period is often marked by micronutrient deficiencies that interfere with optimal growth [2].

Additionally, childhood illnesses such as diarrhea and acute respiratory infections (ARI) are common. For women, improving overall nutritional status throughout the life cycle is crucial to maternal health. Women who become malnourished during pregnancy and children who fail to grow and develop normally due to malnutrition at any time during their life, including during fetal development, are at increased risk of prenatal problems, increased susceptibility to infections, slowed recovery from illness, and possibly death. Improving maternal nutrition is crucial for improving children's health [3].

The poor nutritional status of children and women has been a serious problem in Ethiopia for many years. Therefore, the health sector has increased its efforts to enhance good nutritional practices through health education, treatment of extremely malnourished children, and provision of micronutrients to the most vulnerable group of the population, that is, mothers and children [3]. 


\section{Statement of the problem}

According to the 2008 Human Development Index, 38 per cent of children in the world are underweight, 16 per cent are stunted and 6 per cent are wasted [4]. The poor nutritional status of children and women has been a serious problem in Ethiopia for many years. The level of childhood mortality in Ethiopia has been rated highest in the world and children under five have been recognized as the most vulnerable group of malnutrition [5]. Concerning with progress of combating child under nutrition a comparison of data of 2005 and 2011 EDHS showed that there had been some improvements in the nutritional status of children.

The percentage of children stunted fell by $3 \%$ from 47 in 2005 to be 44 percent. In general, the prevalence of stunting increases as the age of a child increases, with the highest prevalence of chronic malnutrition found in children age 24-35 months (57 percent) and lowest in children under age six months (10\%) according to 2011 EDHS. Similarly, the percentage of underweight declined by $9 \%$ from 38 percent in 2005 to $29 \%$ in $2011[3,6]$.

There was however no change over six year's period in the percentage of children wasted and stunted. In addition children who survive out of under nutrition lack the physical and mental ability to be productive and innovative which lead again to low social and economic development in the adult life.

Therefore, assessing the prevalence, and practice of mothers on child nutrition and its associated factors is crucial step in designing appropriate strategy in helping the process of reducing less than five children malnutrition.

\section{Significance of the Study}

Mothers/care takers are the most important parts of child care and nutrition. Even though, many studies have been done in Ethiopia to reduce child under nutrition (wasting and stunting), there is no marked decrease in prevalence and effect on future life of children. So thus study also to assess prevalence of mal nutrition in study area it can be important information to take action in redaction of mal nutrition. Thus, any responsible body can use the outcome or result of this study which could be useful tool in designing appropriate strategy. Also, the study may help as a base line for other studies on similar issues.

\section{Objectives}

\section{General objectives}

- To assess the prevalence of malnutrition among under five (6-59 months of age) children in Woreda 06 Addis Hiwot health center, Gulele sub city, Addis Ababa, Ethiopia, 2017.

\section{Methodology}

\section{Study area and study period}

The study was conducted on assessment of prevalence of malnutrition among under five children in gulele sub city woreda 06 governmental health institutions, which is located in Addis Ababa, capital city of Ethiopia to the North of Addis Ababa city. The total populations are 32358 among which 15531 are males and the remaining are females16826. There are 2316 children's aged 6-59 months in Gulele sub city woreda 06 totally.
The population of the woreda is provided by a total of one health center and one private medium clinic. Addis Hiwot Health center is the a governmental health facility though, many studies have been done in Ethiopia to reduce child under nutrition (wasting and stunting), there is no marked decrease in prevalence and effect on future life of children. So thus study also to assess prevalence of mal nutrition in study area it can be important information to take action in redaction of mal nutrition. Thus, any responsible body can use the outcome or result of this study which could be useful tool in designing appropriate strategy. Also, the study may help as a base line for other studies on similar issues.

\section{Specific objectives}

- To determine the prevalence of malnutrition among under five years children in woreda 06 Addis Hiwot health center.

- To assess assosecion focter of malnutrition among under five (6-59 months of age) Glele Sub city Addis Hiwot health center, 2017

which is found in Gulele subcity woreda 06. It is established in 2003E.C, at this time it has 6 beds for inpatient service and serving 32358 populations. Now it is giving service in both preventive and curative aspect for the population.

The study is conducted from April, 2017-July, 2017

\section{Study design}

Institutional based cross sectional study was conducted to determine the nutritional status of children aged 6-59 month in Addis Hiwot Health Center.

\section{Source population}

- $\quad$ All under five children in gulele subcity woreda 6 .

\section{Study population}

- All Under five children aged among 6-59 months in Addis Hiwot health centers.

\section{Selection criteria}

\section{Inclusion criteria:}

- All children among age of 6-59 months in Gulele sub city woreda 06 attending service at Addis hiwot health center was included.

\section{Exclusion criteria:}

- Children who are critically sick

- Children having physical disabilities that can interfere the anthropometric measurement was excluded

- Children less than the age of six months.

\section{Sample size determination}

Hence, sampling size was determined by using the following assumption:

$95 \%$ of CI

\section{A $5 \%$ margin of error}

Then sampling size was calculated by using the prevalence of malnutrition laid by EDHS in 2011 which is $44 \%$ as proportion. 
Citation: Kore C, Ketema A (2018) Assessment of Prevalence of Malnutrition among Children Age 6-59 Months at Woreda 06, Gulele Subcity, Addis Ababa, Ethiopia, 2017. J Nutr Disorders Ther 8: 238. doi:10.4172/2161-0509.1000238

Page 3 of 6

Using single proportion formula the minimum sample size required for the study was obtained

$$
n=\frac{Z^{2} P(1-P)}{d^{2}}
$$

Where: $\mathrm{n}=$ sample size

$\mathrm{P}=$ proportion

$\mathrm{d}^{2}=$ margin of error

$\mathrm{Z}^{2}=$ the value of standard normal distribution corresponding to a significant level of alpha. $\mathrm{n}=(1.96) 20.44(1-0.44) /(0.05)^{2}$ And $\mathrm{n}=378.62816 \approx 379$.

Since the study population $\mathrm{N}=2316$ is less than 10,000 we reduce or adjust the sample size by calculating

$$
\begin{aligned}
& n_{\text {adjusted }}=\frac{n}{1+\frac{n}{N}}=\frac{379}{1+(379 / 2316)} \\
& n_{\text {adjusted }}=\frac{379}{1.16364421} \\
& \mathrm{~N}=325.70029
\end{aligned}
$$

Non respondent rate in this study is estimates to be $10 \%$

i.e. Non respondent $=326 \times 10 \%=326 \times 10 / 100=32.6 \approx 33$

$\mathrm{n}_{\text {correct }}=326+33$

$=359$ Hence an overall sample size is 359

\section{Sampling Technique and Procedure}

By default, mothers or care givers who was came to Addis Hiwot health center are assumed to be random, so voluntary mothers who come to Addis Hiwot health center with children aged 6-59 months at under five OPD and EPI department was included each day until calculated sample size eligible was fulfilled by using non probability sampling as a convenience sampling technique. Using situational analysis, patient flow of Addis Hiwot Health Center at under five OPD and EPI department is approximately 20 children aged 6-59 months per day is from which can capture the sample needed for the study on daily basis.

\section{Data Collection Tools and Procedure}

Before conducting data collection, a structured questionnaire was prepared and tested to address all important variables. The data is collected face to face interviewing mothers/care takers by using pre tested structured questionnaires and direct observing the under five children and assessing of the anthropometry of the under five children.

Data collection was carried out by the trained health worker not engaging in the health care service at the facility with the help of three individuals of principal investigator by assessing the anthropometry measurements.

\section{Data Processing and Analysis}

Each questionnaire was check for completeness, missing values and unlikely responses and then it is manually clean up on such indication. The coded data was entered on to computer using SPSS 21.1 version for its customizing and analyzing.

\section{Study Variables}

\section{Dependent (outcome) variables}

- Level of malnutrition among children aged 6-59 months.

\section{Independent (explanatory) variables}

- Time of initiation of breast feeding

- Duration of Exclusive breast feeding

- Initiation of complementary foods

- Birth order

- Antenatal care history

- Parity

- Feeding practice of mothers/care takers about child malnutrition

- Water and sanitation

- Health services

- Educational status of parents

- Number of children in the households

- Age, Sex, residence, economic status, education status of parents, number of children in the households, occupation, current weight and height the child.

\section{Operational Definition}

\section{Anthropometric measurement}

A set of noninvasive, quantitative techniques for determining a Childs body fat composition by measuring, recording, and analyzing specific dimensions of the body, such as height and weight; skin-fold thickness; and bodily circumference at the wrist, hip, and chest.

\section{Nutritional status}

The condition of the body as a result of the intake, absorption and use of nutrition and the influence of disease-related factors.

\section{Nutritional assessment}

A structured way to establish nutritional status and energyrequirements by objective measurements and whereby, completed with objective $\mathrm{p}$ arameters and in relation to specific disease-indications, an adequate (nutritional-) treatment can be developed for the patient.

\section{Malnutrition}

A condition that occurs when body does not get enough nutrients.

\section{Under nutrition}

A health state in which a child's nutrient requirement is not being met.

\section{Stunting}

Reflects chronic under nutrition during the most critical periods of growth and development in early life. It is defined as the percentage of children aged 0 to 59 months whose height for age is below minus two standard deviations (moderate and severe stunting) and minus three standard deviations (severe stunting) from the median of the WHO Child Growth Standards. 


\section{Underweight}

Is a composite form of under nutrition that includes elements of stunting and wasting. It is defined as the percentage of children aged 0 to 59 months whose weight for age is below minus two standard deviations (moderate and severe underweight) and minus three standard deviations (severe underweight) from the median of the WHO Child Growth Standards

\section{Wasting}

Reflects acute under nutrition. It is defined as the percentage of children aged 0 to 59 months whose weight for height is below minus two standard deviations (moderate and severe wasting) and minus three standard deviations (severe wasting) from the median of the WHO Child Growth Standards

\section{Ethical consideration}

A letter of support was written from Rift Valley University Research and Publication office, to get permission from Addis Hiwot Health center and Woreda 06 health center. The participant of the study subject was given adequate information and explanation about the purpose of the study. Oral consent was obtained from each study participant before making exit interview and confidentiality was kept. Anonymity was maintained for those record reviews.

\section{Result}

The majority of age of child was 6-12 months 260 [72.4\%] from $13-24$ months are 87[24.2\%] and from 25-36 months are 12[3.3\%]. Regarding the sex of child respectively Male 179[49.9\%] the remaining are Female 180 [50.1\%]. Place of health service and delivery regarding data in Hospital, Health center, Home and the list other respectively 66[18.4\%] $257[71.6 \%$ ] 25[7.0\%] 11[3.1]). Known 312[86.9\%] the other is $47[13.1 \%]$ unknown their weight of birth. The reason for visit for the child was as sick child 204[56.8\%] and the well-baby 155[42.2\%].

Regarding child assessing the most had regular breast feeding 324 [90.3] the other had no breast feeding at the visit 35[9.7\%].

The frequency of breast feeding per day for the breast feeding children is 1-3 times per day $114(31.8 \%), 6-4$ times per day 112 (31.2\%), and greater than six times daily are 117 (32.6\%).

The time to start breast feed their children is 1-6 hours after delivery of 282 (78.6\%), 7-24 hours 49 (13.6\%), and greater than 24 hours 21 (5.8\%).

The duration of exclusive breast feeding 1-3 months 279 (77.7\%), 4-6 months 72 (20.1\%) and others 8 (2.2\%).

Mother who gives Supplementary feeding is 353 (98.3\%) and who do not start giving supplementary food 6 (1.7\%) The time for start giving supplementary feeding is, at 6month 164 (46.6\%) greater than 6 month 195 (54.3\%). The type of supplementary food is cow milk 100 (27.9\%), milk powder $162(45.1 \%)$, porridge $85(23.7 \%)$ and other kind of food $12(3.3 \%)$.

All children are received immunization and diarrheal disease among children is $83(23.1 \%)$. Hand washing practice of parents is water only $96(26.7 \%)$, sometimes with soap 260 (72.4\%) and always with soap $3(0.8 \%)$. The source of drinking water for the families which are protected are $353(98.3 \%)$ and those who use unprotected water source are6 (1.7\%).
On the attitude of parents on benefit of colostrums feeding those agreed are 339 (94.4\%) and those who disagree are 20 (5.6\%).

Attitude of parents on advantage of exclusive breast feeding who are agreed are $345(96.1 \%)$ disagree $14(3.9 \%)$. Altitudes on the benefit of fluid intake during diarrhea, those who agree are 340 (94.7\%) and disagree $19(5.3 \%)$. The attitude of parents on the advantage of nutritional status follow up, those who agree are $345(96.1 \%)$ and disagree 14 (3.9\%). The attitude toward uses of more food intake for lactating mothers, those who agreed are 350 (97.5\%), and those who disagreed are $9(2.5 \%)$, the attitude about raw butter feeding for new born, those who agree 303 (84.4\%) and those who disagree 56 (16.6\%). Growth monitoring, weight for age of children shows, normal 165 (46\%), mild 160 (44.6\%) moderate 34 (9.5\%).

MUAC measurement shows normal 159 (44.3\%) wasted 160 (44.6\%).Discussion

In this study we attempted to assess the prevalence of malnutrition among children under 5 years of age [7].

From this study we learn that high proportion of children experience sickness. There were a large number of women visiting sickbaby clinic.

More than half of the children had recent episodes of diarrhea at the time of interview. The lack of proper hand washing in handling babies could contribute to these episodes [8].

Considering that over $9.7 \%$ of babies were not breastfed, this may contribute to illnesses observed in these children. Exclusive breastfeeding is recommended, but most of the women do not seem to know or follow the healthy recommendations [9]. High proportion of women seems to visit wellness baby clinic only when their babies are sick and not for monitory purposes. Growth monitory and nutritional assessments are recommended for raising healthy children. Mothers also lack adequate nutrition during lactating and this may contribute to postnatal malnutrition among Ethiopian children [10].

We found that about $66.6 \%$ of women have a family size of $4-6$ including high level of parity. Considering the level of family income in the report, although we do not have adequate information, it seems that family size is too large to be affordable by many parents [11].

Over $11.4 \%$ of women reported that children are raised by single mothers, perhaps because of either teen-age pregnancy or unstable marriages.

Most of the women in this study site come for service to the clinic from urban areas and moderately literate.

This study tries to assess the magnitude of malnutrition and nutritional status using anthropometric measurement. Depending on the information collected and parameters used to examine the study participant's nutritional status, we just try to verify it in the following manner [12].

\section{Weight for age}

From the study participants assessed their nutritional status, more than half of them (194) were identified to have malnutrition. From this, a total of 160 were found to have mild malnutrition while 34 of them have moderate type of malnutrition. Totally, large number (54.1\%) of our study participants was revealed to have different malnutrition status by weight for age [13]. 


\section{Weight for height}

From all of study participants, 207(57.7\%) them have classified to different malnutrition status with weight for height. Depending on this parameter, our study participants are categorized to mild wasting 198(55.2\%), moderate wasting 7(1.9\%) and severely wasted $2(0.6 \%)$.

\section{MUAC (mid upper arm circumference)}

Nearly less than half of total study participants were found to be malnourished during the assessment period from which $178(49.26 \%)$ of them were classified as having wasting using Mid Upper Arm circumference as measurement parameter. Generally, this study assesses different nutritional status using the above anthropometric measurements and classifies it which was $0.6,1.9$, and 55.26. And 42.3 severe wasting, moderate wasting, mild wasting and normal growth status respectively by weight for height as well as normal. On another hand the study identifies, moderately malnourished 9.5\%, mild malnutrition $44.6 \%$ and normal growth are $46.0 \%$ status respectively using weight for age [14]. Even though the result of this study varies in some parameters there is a high prevalence of wasted (49.26\%) among the study population which is significantly greater the study done by EDHS 2011 (9\%) by weight for height [15]. On other hand the study conducted by EDHS in 2011 at Amhara region indicates the prevalence of severe wasting as a form of malnutrition which is $14.8 \%$ and greater than our study finding $0.6 \%$ but the magnitude of wasting was $49.26 \%$ and this is much number [16].

\section{Conclusion and Recommendation}

\section{Conclusion}

In conclusion, this study developed a cross-sectional survey to collect information to understand the probable association of malnutrition and demographic, cultural and socio-economic factors in children under 5 years of age. This study identified that, the source of information is mostly from mothers and large number of women deliver at Health center. The majority of the women were from urban and they are literate with low income, yet with large family sizes, more than half of the children experience malnutrition and episodes of diarrhea. The majority of children assessed were in age group of 6-12 months with unknown weight during their neonatal period presented at sick baby clinic. Most of the children were exclusively breastfed starting from 0-6 hours of their life at frequency of more than six times per day regularly. More than half of the parents start their children supplementary feeding at the age of after six months and fully immunized their children. The water supply of the parent was mostly protected and majority of mother has good hand washing practice. Majority of the care taker for the children has better understanding and positive attitude towards colostrums feeding of neonates, exclusive breast feeding and follow up the nutritional status of their children. This study also identifies the prevalence of malnutrition and classifies it according its degree which is $55.1 \%, 57.7$ and 49.26 measured with weight for age, weight for height and mid upper arm circumference respectively.

\section{Recommendation}

Our study has a number of limitations and from this study alone we cannot conclude definitive causative association. Our recommendation from this study is further systematic study looking into causative associations between comprehensive analysis of malnutrition and associated factors should be done in the future. We also recommend other stake holders who are responsible to alleviate socioeconomic problem which is the major factor that hinders the care takers feeding their child balanced diet. The woreda health office and the Addis Hiwot health center should intensify their effort in utilization of family planning coverage and collaborating with other stake holders to minimize malnutrition problem in the community.

Finally, since malnutrition results from multi socioeconomic factors multisectoral collaboration should implemented for alleviation of malnutrition problem from woreda health office, Addis Hiwot health center, woreda finance and economic office and woreda urban agriculture extension.

\section{Acknowledgement}

I would like to express my great appreciation to my advisor $\mathrm{Mr}$. Cheru Kore for his initiation to prepare a research paper expecting our real thesis more accurate one, guidance and technical support for our study.

\section{References}

1. Black Re, Morisss, Baryce J (2003) Where and why are 10 million children dying every year? Lancet 361: 2226-2234.

2. United Nations Children's Fund (2009) The state of World's children 2009. Special edition: celebrating 20 years of the conception on the right of the child. New York: United Nations Children's Fund.

3. Central Statistical Authority (2011) Ethiopian Demographic and Health Survey. Central Statistical Authority (CSA), Addis Ababa, Ethiopia.

4. Central Statistical Agency [Ethiopia] and ORC Macro (2006) Ethiopia Demographic and Health Survey. Addis Ababa,Ethiopia.

5. Planning and Programming Department Health Sector Strategic Plan (HSDP-3) (2005) 2005/6-2009/10. FMOH,Addis Ababa,Ethiopia.

6. Central Statistical Authority (2006) Ethiopian Demographic and Health Survey. Central Statistical Authority (CSA),Addis Ababa,Ethiopia.

7. Black Re, Allen LH, Bhutta ZA, Caulified LE, Deonis M, et al. (2008) Maternal and child under nutrition: global and regional exposures and health consequences. Lancet. 371: 247-260.

8. UNICEF Children and the Millennium Development Goals (2007) Progress for children a report card on nutrition.

9. Uthman OA (2009) Using extended concentration and achievement index to study socioeconomic in equalities in chronic malnutrition; the case of Nigeria. International journal for equity in health 8: 22.

10. Black R, Allen I, Bhutta Z, Caulfield EL, de Onis M, et al. (2008) Maternal and child under nutrition: global and regional exposures and health consequences 371: 243-260.

11. Gupta MC, Manjusha M, Sunita A, Meenakshi S (1991) Relation of Childhood Malnutrition to Parental Education and Mothers' Nutrition Related KAP. Indian J Pediatr 58: 269-274.

12. Ministry of Health (MOH)[Ethiopia] (2005) The Health Sector Strategic Plan (HSDP-3). MOH, Addis Ababa, Ethiopia.

13. Central Statistical Agency Addis Ababa, Ethiopia. Ethiopia Demographic and Health Survey 2011(ESARO) Nairobi, Tulane University, USA.

14. Beka T, Wambui K, Zewditu G, Girum T (2009) Magnitude and determinants of stunting in children under five years of age in food surplus region of Ethiopia: The case of West Gojam Zone. EJHD 23: 2

15. Clara A (2001) A longitudinal, prospective study of daily feeding practices, health and growth in a sample of Swedish infants, Comprehensive Summaries of Uppsala Dissertations from the Faculty of Medicine:1016.

16. FAD/FAO/WFP (21) the state of food in security in the world in Rome Italy FAO. 